\title{
The role of contracting strategies in social value implementation
}

Bankole O. Awuzie PhD

Post Doctoral Research Fellow, Unit of Lean Construction and Sustainability, Department of Built Environment, Central University of Technology, Bloemfontein, South Africa (corresponding author: Bawuzie@cut.ac.za)
Peter McDermott PhD

Professor of Construction Procurement, School of the Built Environment, University of Salford, Salford, UK

There has been an increasing demand for social value (SV) implementation to assume a cardinal position in the infrastructure delivery efforts of infrastructure client organisations (ICOs). However, whereas successful implementation has been recorded in some projects, monumental failures have also been recorded in others. This variance in implementation performance is a cause for concern. The mode of governance applied in an infrastructure delivery endeavour has been identified as capable of influencing the implementation of SV. This observation makes imperative an investigation into the role of contracting strategies - an integral part of governance modes - adopted by ICOs on SV implementation performance. This is the aim of this study. Using a case study approach, three infrastructure projects which used different contracting strategies were selected from two different countries, the UK and Nigeria. Semistructured interviews were conducted with ICO representatives on these projects and subsequently analysed using qualitative content analysis. Findings confirmed that the kind of contract adopted by ICOs influenced their ability to drive the successful implementation of desirable SV objectives through their supply chain. It is therefore recommended that ICOs ensure that the selected contracting strategies are capable of ensuring successful implementation of the desired objectives.

\section{Introduction}

Infrastructure client organisations (ICOs) have consistently indicated their willingness to implement social value (SV) through their activities. This is in response to increasing calls by successive governments and civil society groups alike (IUK, 2013). The procurement and subsequent delivery of infrastructure projects has been identified as a significant facet through which this can be achieved (Calderon and Serven, 2008; Snieska and Simkunaite, 2009; Watermeyer, 2003; Wells and Hawkins, 2008). However, various studies into the efforts of these ICOs have reported varying implementation outcomes. Whereas some infrastructure projects have recorded successful implementation, others have failed to do so. Such variance is a cause for concern, thus making the need for an investigation into the mode of organisation and management of the infrastructure delivery process imperative. The contracting strategy adopted in governing extant relationships within the delivery system constitutes a significant component of its governance arrangements (Carroll and Burton, 2012). As such, this study is directed at investigating the influence of the adopted contracting strategy on the ICO's ability to drive successful implementation through its supply chain as epitomised by the delivery system.

Construction industry clients such as ICOs have been advised to align their organisational procurement strategy with an appropriate contracting strategy to attain the delivery of their strategic objectives. Given the advent of the sustainability agenda, such strategic objectives have come to consist of the attainment of social, economic and environmental sustainability parameters beside factors such as time, cost and quality. SV and its variants, such as local content development policies, are situated within the realm of socioeconomic sustainability. They have become topical issues in both developed and developing countries. In the UK, the advocacy for the attainment of SV in infrastructure delivery has been championed by governmental and non-governmental bodies alike. Examples of such agents include Infrastructure UK (IUK) and Engineers against Poverty (EAP). In Nigeria, the Nigerian Oil and Gas Industry Content Development (NOGICD) Act is a government-sponsored legislation (MPR, 2010) with tenets similar to the Public Services (Social Value) Act 2012 (2012). A significant distinction between the two legislations is that whereas the former is mono-sectoral in nature, primarily focusing on activities within the Nigerian oil and gas industry, the latter is concerned with project procurement activities spanning various sectors of the UK economy. Also, the NOGCID Act is a prescriptive legislation replete with penalties for non-adherence. Such penalties as contained in the act include the blacklisting of erring companies from participation in the nation's oil and gas industry among others which are published in section 2 of the act. On the other hand, the Public Services (Social Value) Act 2012 (2012) only seeks to encourage ICOs and other supply chain members to strive towards successful implementation of SV. Hereafter, both acts will be referred to collectively as SV for easy comprehension. 


\section{Offprint provided courtesy of www.icevirtuallibrary.com Author copy for personal use, not for distribution}

The NOGICD Act (MPR, 2010) was enacted in 2010 by Nigeria's executive and legislative arms of government with the intent of curbing capital flight and increasing the levels of indigenous participation in the oil and gas sector of the nation's economy. It was expected that the act would lead to the increased empowerment of the populace through capacity, job and wealth creation. Arguably, these expectations place the act in good stead as a derivative of the SV agenda. The act consists of 107 sections and applies to all operators (ICOs), contractors and various entities concerned with several activities within the oil and gas sector. Central to the NOGICD Act (MPR, 2010) is the accordance of preferential treatment to Nigerian-owned companies in the award of contracts. Also, evidence of compliance with the tenets of the act as it pertains to the development of indigenous competencies by foreign owned firms shall remain a deciding factor in the continued engagement of such firms in the sector.

Three years into the post-NOGICD Act era, available evidence points to the continued inability of the ICOs in the nation's oil and gas industry to ensure successful SV implementation during infrastructure delivery activities (Balouga, 2012), the NOGICD Act (MPR, 2010) notwithstanding. This is evident in the deteriorating welfare standards of its citizenry among other criteria. The doctoral study of which this study forms an integral part was commissioned to explore possible avenues through which this anomaly can be corrected (Awuzie, 2014).

According to extant studies, ICOs are expected to assume leadership in championing the implementation of $\mathrm{SV}$ within their respective projects, particularly during the procurement and delivery stages (Dorée et al., 2011; Wells and Hawkins, 2008). Studies have shown instances where ICOs have coordinated successful implementation of SV (Dorée et al., 2011; Warner, 2011). The selection of an appropriate contracting strategy has been identified as one of the salient factors impacting upon an ICO's ability to drive the implementation of SV effectively (Esteves et al., 2009; Warner, 2011). As such, ICOs have been admonished to exercise caution in the selection of the appropriate contract for delivering SV outcomes (IUK, 2013).

Unfortunately, there appears to be a paucity of empirical studies looking into the relationship between SV implementation performance at project level and the type of contracting strategy adopted. Also, the influence of contracting strategies on an ICO's ability to drive successful SV implementation has been under-investigated (Warner, 2011). Such studies have become imperative as they highlight the critical attributes to be considered by any ICO which is interested in delivering SV in the selection of appropriate contract strategies. This study seeks to contribute towards the development of a theory of successful SV implementation by investigating the relationship between the contracting strategy adopted by an ICO and the influence of such a contracting strategy on the ICO's ability to ensure successful SV implementation.
To achieve its objective, this study is divided into five sections, namely, an explanation of SV as a variant of socioeconomic sustainability, a brief review of the implementation and contract strategy literature, a brief narrative detailing the research methodology used, presentation and discussion of the findings and the conclusion.

\section{Social value as a socioeconomic sustainability outcome}

The term 'SV' has continued to defy any widely accepted definition. Its various definitions are contingent upon the realm within which it is being applied. For instance, Wood and Leighton (2010) define it as the 'soft' non-financial impact of organisations, programmes of work and investments which may include, but is not limited to, communities', individual and, in certain cases, environmental well-being. Furthermore, Russell (2013) defines $\mathrm{SV}$ as the outcome benefits of certain activities, performed by any organisation, which are important to the organisation's stakeholders. Similarly, Mulgan (2010) defines SV as the value that non-governmental organisations, social enterprises, social ventures and social programmes create. According to the Public Services (Social Value) Act 2012 (2012), SV can be defined as the notion of maximising additional outcomes developed through procuring goods and services which surpass the initial benefit of the goods and services themselves. This proliferation of definitions demonstrates the subjective nature of SV and hence renders its measurement and enforceability through conventional contracts difficult (Wood and Leighton, 2010).

In this study, SV for ICOs is defined as the additional outcome of their investment programs, delivered through organisational funds, towards their local communities varying from using local suppliers, employing local work forces and creating apprenticeships opportunities. This definition is engendered by the stipulations of the Public Services (Social Value) Act 2012 (2012) and the NOGICD Act as well as views espoused by Watermeyer (2000) and Wells and Hawkins (2008). The increasing adoption of SV as a project outcome and the need to ensure that ICOs are suitably positioned to drive its implementation render this study imperative. Undoubtedly, there is need for the creation of effective relationships within the supply chain by ICOs to engender successful implementation. It is this study's major proposition that the ability of an ICO to achieve successful implementation is significantly influenced by the type of contracting strategy it adopts. This proposition is buttressed by similar propositions proffered by Rwelamila et al. (2000) on the inability of construction projects to deliver on sustainability parameters due to inappropriate organisational structures and the unsuitability of the traditional contract strategy for the attainment of such purposes.

\section{Procurement systems as mediums for SV implementation}

Procurement systems in construction have been defined by Rwelamila (1996), as cited in the paper by Rwelamila et al. (2000), as 'the organisational structure adopted by Clients for the 


\section{Offprint provided courtesy of www.icevirtuallibrary.com Author copy for personal use, not for distribution}

management of the design and construction of a building project'. Rowlinson (1999: p. 29) describes it as being 'about the acquisition of project resources for the realization of a constructed facility'. McDermott (1999) refers to the International Council for Building and Construction Working Group 92's definition of construction procurement as a framework within which construction is brought about, acquired or obtained. Furthermore, he identifies the components of an effective procurement system as consisting of the several methods employed in the design and construction of the given facility; the cultural, managerial, economic, environmental and political issues which might affect the procurement process.

Rowlinson (1999) asserts that what has been typically referred to as procurement systems - namely, design-and-build, traditional and divided contract approaches - are not really procurement systems but rather contracting strategies. He admits that these contracting strategies - alongside other variables such as the national culture, organisational form, payment methods, overlap of project phases, selection process, source of project finance, contract documents, leadership, authority and responsibility, and performance - form what could be referred to as a procurement system.

The place of the procurement system as a medium for implementation of policies or organisational strategy was brought to the fore in the statement credited to Andrew Smith, former Secretary to the Treasury (Erridge, 2007), wherein he stated that 'good procurement is essential to the success of the government's programmes; it provides the link between policy and delivery'.

This statement accentuates the centrality of procurement systems in the implementation of strategic objectives such as SV. According to Hill and Hupe (2009), procurement systems have to be effectively governed for successful implementation. For this to happen, a thorough understanding of the procurement system's multi-process, multi-actor, inter-organisational and multi-layered characteristics is necessary. Furthermore, the roles of the various actors within such inter-organisational contexts should be understudied. This is particularly so as it pertains to the relationships between ICOs and their supply chains within the infrastructure delivery system (IDS). Such understanding is expected to lead towards the development of an in-depth knowledge of the capabilities of the procurement system's components in enhanced SV implementation performance. Also, it allows for the introduction of new measures aimed at optimising these established capabilities to achieve successful implementation.

\section{Contracting strategy}

This study identifies with the definition of contracting strategies as rendered by Rowlinson (1999). A choice of contracting strategy is indeed significant as it provides the platform upon which construction clients coordinate construction activities and exchange relevant project information with other project stakeholders with the intention of achieving their organisational strategic objective (de Blois et al., 2011). According to the Irish Department for Public Expenditure and Reform's report on procurement and contract strategy, the primary consideration in the procurement of construction projects is the need to match the correct organisational procurement strategy with the appropriate contracting strategy so that value for money is obtained (DPER, 2012). Simply put, the kind of contracting strategy adopted by ICOs has the potential to influence its ability to oversee SV implementation during project delivery. According to Walker and Rowlinson (2007), the choice of a proper contracting strategy revolves around four main decisions: setting the project objectives and constraints; selecting a proper project delivery method; selecting a proper contract form; and contract administration practices. Also, factors to be considered when selecting a suitable contracting strategy should normally include the optimal level of risk which the contracting authority wishes to transfer, what total risk is tolerable for contractors and what needs to be done to achieve optimal risk transfer.

Expectedly, the contracting strategy should support the ICO's main project objectives in terms of risk allocation, delivery, costs and the attainment of sustainability outcomes such as SV (Kumaraswamy and Dissanayaka, 1998). The organisation and governance of the inherent inter-organisational relationships in the IDS is based mainly on the kind of contracting strategy adopted. Furthermore, the ability of an ICO to communicate its strategic objectives and subsequently to coordinate activities of the entire supply chain during the delivery process to attain such objectives is largely dependent upon this organisational framework (Carroll and Burton, 2012). Appropriate contracting strategies contribute towards the proper flow of project know-how as well as the setting up of effective and efficient communication structures within the delivery system (Emmitt and Gorse, 2006). Therefore, it would appear that contracting strategies undoubtedly have a significant influence on SV implementation, particularly as it pertains to the power of the ICO's ability to drive it within the IDS (Cherns and Bryant, 1984). However, there is a seeming paucity of empirical studies which have attempted to investigate this phenomenon, hence necessitating this study.

Although a plethora of contracting strategies is available to ICOs, some of these strategies are predominantly used in projects domiciled in certain sectors. For instance, in the building sector, strategies such as design-bid-build and design-and-build are usually prevalent. In major infrastructure projects for the oil and gas as well as transportation sectors, strategies such as engineering, procurement and construction (EPC) and build, own, operate and transfer (BOOT) projects are often adopted. Because of this study's focus on investigating the influence of contracting strategies on an ICO's ability to drive successful SV implementation within the IDS in the Nigerian oil and gas industry, contracting strategies predominant within the sector such as the engineering, procurement, construction management (EPCM) and EPC were adopted. Occasioned by the need to achieve theoretical replication through comparisons to SV implementation in the UK's transportation sector (Yin, 2009), a project which was governed by a design, construct and maintain (DCM) contracting strategy was selected. 


\section{Offprint provided courtesy of www.icevirtuallibrary.com Author copy for personal use, not for distribution}

\section{Methodology}

This study reports an integral part of a doctoral research study conducted between 2011 and 2014. The main study is premised on an abductive, qualitative and multi-case study research strategy. The choice of abductive reasoning is predicated on the researchers' desire to apply an extant theoretical foundation in making sense of the phenomena being understudied (Dubois and Gadde, 2002, 2014; Leiringer et al., 2009; Yin, 2009). As such, the concept of systems viability (Beer, 1984) is used to gain an in-depth understanding of the extant relationships between the ICO and other project stakeholders within the IDS. It also provided the researchers with an underlying theoretical lens upon which the investigation into the influence of contract strategies on the ICO's capability to spearhead the successful SV implementation within this complex web of inter-organisational relationships (IDS) was premised (see Awuzie and McDermott (2014)). This IDS serves as the unit of analysis for the study.

The ability of the case study strategy to enable the study of a phenomenon in its natural context (Eisenhardt and Graebner, 2007) and the opportunity it provides for multiple data sources (Yin, 2009) makes it a natural choice for this study. This strategy not only engendered the study into the influence of contracting strategies on the client's ability to coordinate its supply chain for successful SV implementation from a systemic perspective - the IDS - but also provided the opportunity for data collection from several sources. Also, Dickinson et al. (2007) in a longitudinal study into the implementation of policy through construction procurement attest to the profoundness of case studies in enabling an in-depth understanding of process-based activities. However, Dubois and Gadde (2002) observe certain shortcomings of the strategy particularly confronted with the dilemma of handling the interrelatedness of the several elements and factors evident in a research activity. This hindrance has been effectively countered in this study through the introduction of the viable infrastructure delivery model (VIDM) - a model for assessing the effectiveness of relationships within such project delivery systems. The multilayer and recursive nature of the VIDM allowed the researchers to apply it in the identification of these interrelationships within case studies (Awuzie and McDermott, 2015).

The selection of cases remains pivotal to conducting successful case study research (Eisenhardt, 1989; Yin, 2009). As such, researchers are expected to approach this task with caution. In this study, the underlying rationale for commissioning this study informed the selection criteria. The doctoral study of which this study forms an integral part was commissioned to investigate the cause for poor implementation of the NOGICD Act (MPR, 2010) during the conduct of activities such as the delivery of infrastructure in the Nigerian oil and gas sector. Based on the foregoing, three IDSs were selected for the study out of an expected initial sample of seven cases. While two of these IDSs were responsible for the delivery of two distinct infrastructure projects within Nigeria's oil and gas industry using different contracting strategies, a third IDS was selected from the UK's transport sector to allow for theoretical and literal replication, respectively. The desire to achieve both a cross-contextual comparison of SV implementation at project level and convenience led to the choice of the UK as the research study was being majorly carried out in the UK. One of the Nigerianbased IDSs was instrumental to the delivery of a project - the floating production storage and offloading (FPSO) X - which has won global acclaim for its achievements regarding successful SV implementation performance.

Semistructured interviews and project and policy document reviews were adopted as sources of data. These techniques provide appropriate platforms for unrestricted expression of personal perspectives (Awuzie and McDermott, 2015) and come highly recommended by several researchers (Denscombe, 2007; Hartley, 1994; Kvale, 2006; Miles and Huberman, 1994). A total of 27 face-to-face semistructured interviews were conducted with representatives of the organisations within each IDS. These interviews lasted for approximately $1 \mathrm{~h}$ each. They were also conducted across three distinct locations in two countries, Nigeria and the UK, between November 2012 and April 2013. Interviewees were asked to share their experiences pertaining to SV implementation while working on the projects. Questions which sought to inquire into the role of the ICOs during the delivery process in providing the desired leadership were also asked. Leadership in this case was identified as the ability of the ICO to define clearly the project deliverables alongside the SV components of such deliverables during the inception stages; the ability vividly to place SV into the mainstream of procurement processes; the ability to develop effective institutional apparatus for coordinating, controlling and auditing SV implementation within the IDS during the delivery process proper; and lastly, the ability of the ICOs to assume direct responsibility for successful implementation.

The emergent data were subsequently analysed using qualitative content analysis through the aid of pre-set themes (Taylor-Powell and Renner, 2003). Accordingly, the findings were then applied in testing the study's central proposition which had been stated previously.

\section{Description of cases}

The selected cases, the component stakeholders and the number of interviewees representing these stakeholders within each IDS are listed in Table 1.

\subsection{IDS1}

The IDS1 is a project delivery system (temporary multiorganisation (TMO)) which was responsible for the entire development of a FPSO facility. This FPSO is presently located within one of Nigeria's largest single deep-water oil fields in the country's Niger Delta region. The field upon which it is situated possesses an estimated 550 million barrels of crude oil, thus making it a significant project. The EPCM contract for the delivery of the FPSO was awarded in 2008 and delivered in 2011. 


\begin{tabular}{|c|c|c|c|}
\hline Case & Description & Stakeholder group & $\begin{array}{l}\text { Number of } \\
\text { interviewees }\end{array}$ \\
\hline \multirow[t]{3}{*}{ IDS1 } & $\begin{array}{l}\text { Project team responsible for the delivery of an FPSO unit in Nigeria. } \\
\text { Contract strategy (EPCM) }\end{array}$ & $\begin{array}{l}\text { Infrastructure client organisation } \\
\text { (operator) }\end{array}$ & 4 \\
\hline & & EPCM contractor & 3 \\
\hline & & Subcontractors & 5 \\
\hline \multirow[t]{3}{*}{ IDS2 } & $\begin{array}{l}\text { Project team responsible for the delivery of a PP in Nigeria. } \\
\text { Contract strategy (EPC) }\end{array}$ & $\begin{array}{l}\text { Infrastructure client organisation } \\
\text { (NigCorp) }\end{array}$ & 3 \\
\hline & & EPC contractor & 1 \\
\hline & & Subcontractors & 6 \\
\hline \multirow[t]{3}{*}{ IDS3 } & $\begin{array}{l}\text { Project team responsible for the delivery of a tram line project }(L R) \text { in } \\
\text { the United Kingdom. }\end{array}$ & $\begin{array}{l}\text { Infrastructure client organisation } \\
\text { (Transerv) }\end{array}$ & 3 \\
\hline & Contract strategy (DCM) & DCM contractor & 1 \\
\hline & & Subcontractor & 1 \\
\hline
\end{tabular}

Table 1. Description of cases

The cost of the project was given as US\$ $0 \cdot 8$ billion. The FPSO, hereafter referred to as 'FPSO X', was designed to handle 200000 barrels per day, 350 million cubic feet of gas production and an injection of 300000 barrels of water into the vessel per day. It is also expected to have a life span of 18 years at its present location in the Niger Delta region. The FPSO X project was carried out in stages across different countries, including Nigeria.

The FPSO X project was delivered through the EPCM. Therefore, IDS1 was bound by the tenets of this contract strategy. Under this strategy, the ICO retained the responsibility for the majority of the project risks, while the contractor bore a significantly smaller proportion of such risks. However, the contractor undertook to manage the project on behalf of the client. In IDS1, the ICO, referred to as the operator, recruited the EPCM contractor as well as the subcontractors. Furthermore, the ICO bore responsibility for the payment of these parties and maintained a regular interface with the contractor and the subcontractors, separately or jointly as the case may be.

\subsection{IDS2}

The Pipeline Project (PP) is a project being delivered by the Nigerian Corporate, hereafter referred to as NigCorp. NigCorp was awarded the contract for the construction of a $180 \mathrm{~km}$ long pipeline traversing a total of 132 different communities across three states within Nigeria's Niger Delta region, in July 2010. The contract was awarded under an EPC contract to another wholly Nigerian-owned EPC contractor. Actual construction commenced in October of the same year. The delivery of PP was carried out in two phases. This study is concerned with phase 1 which was worth an estimated $\$ 270$ million measuring approximately $101 \mathrm{~km}$ long and traversing 112 communities across two different states. This phase of the project was commissioned in September 2012. It involved the laying of a 42 inch $(1.07 \mathrm{~m})$ dia. pipeline over the above-mentioned distance. The IDS2 for phase 1 consisted of several Nigerian suppliers, the lead contractor and regulatory authorities.

The EPC strategy was adopted in the delivery of the PP. Expectedly, relationships within IDS2 were governed by the dictates of the EPC contract strategy. Under this strategy, the ICO selected the contractor, who in turn was responsible for the selection of the entire supply chain. The contractor assumed control over activities relating to the engineering design, procurement and construction. Under such contracts, the contractor is mandated to deliver a finished facility to the ICO for an agreed-upon price and at a definite date, alongside other specifications as prescribed by the ICO. He has to deal with the owner and also with the subcontractors and consultants during project delivery. The owner's responsibility ends with the award of the contract, while the contractor's responsibility commences at this point. In a nutshell, under the EPC, the ICO allocates the responsibility for SV implementation to the main contractor.

\subsection{IDS3}

As a project delivery system, the IDS3 consisted of the TMO responsible for a light rail project, referred hereafter as the 'LR project'. This LR project is situated in one of the major cities in the North West region of England. The delivery of the LR project is being executed in phases, with the first phase dating back to 1988 when approval was secured from government for its development; it was commissioned in 1992. Subsequent phases have been delivered since then and the entire length of the LR project which has been delivered to date measures an estimated 48.5 miles $(78 \mathrm{~km})$, with 77 stops. It is expected that upon completion of the second leg of the third phase of the LR project in 2016/2017, the entire project length would be within the region of 59 miles $(95 \mathrm{~km})$ and 93 stops. Also, the LR project, when 


\section{Offprint provided courtesy of www.icevirtuallibrary.com Author copy for personal use, not for distribution}

completed, will transverse at least seven of the ten boroughs of this major city.

This study is primarily concerned with the first leg of the third phase of the LR project, dubbed phase $\mathrm{X}$ (a). Construction work on phase X (a) commenced immediately after government approvals, and funding were secured in 2008. It was fully commissioned in December 2012, running several months behind schedule. The project was let on a DCM contract basis by the client authority, a subregional transport authority hereafter referred to as TranServ. The DCM contract was won by a consortium which was composed of a leading UK-based construction company, a rail infrastructure provider and a signals company.

The DCM contract allows for the combination of ownership interests between the purchaser (ICO) and the contractor in such a manner that the contractor designs, constructs and maintains the asset to provide services that are subsequently bought by the client (Carmichael, 2000). This strategy has been cited as often used in the delivery of similar long-standing infrastructure across the globe (Carmichael, 2000; Ottosson, 2012). Such an approach is dependent upon prediction over a significant time, spanning the operation and maintenance costs for the project.

DCM has been lauded as possessing the ability to deter the contractor from delivering at lowest cost as he (the contractor) has an ongoing obligation into the future. This form of contract also has a long-term orientation during which the contractor is engaged over the entire agreed-upon duration, thus allowing him to innovate continually.

\section{Findings and discussion}

Arguably, the manner in which an IDS is designed has been noted to influence significantly the level of communication and collaboration between its component parts, especially between the ICO and other stakeholders (Carroll and Burton, 2012). Similarly, Stoker (1998) observes the importance of effective organisational governance structures in ensuring successful project performance. Olsen et al. (2005) observe that the choice of contracting strategy for any particular project should be dependent on what the ICO wants to achieve. Esteves et al. (2011) and Schramm et al. (2010) further admit to the centrality of contracting strategies in the attainment of an ICO's objective, especially as it pertains to enhanced SV performance. These assertions necessitate an investigation into the impact of the various contracting strategies on the ICO's ability to drive effective SV implementation through its delivery system.

Findings indicate that the type of contracting strategy affects inter-organisational relationships within the respective IDSs, particularly as it relates to the degree of communication and collaboration between the ICO and project stakeholders and the successful SV implementation. Within IDS1, there were no complaints by the subcontractors about late payment, whereas in IDS2, the subcontractors interviewed maintained that their payments were delayed by the main contractor for 4 months. Prompt payment of subcontractors is an established means of encouraging local subcontractors to participate in the delivery of projects. Although both ICOs in IDS1 and IDS2 maintained their desire to implement provisions of the NOGICD Act as it concerns local supplier development and engagement on fair terms, the contract strategy adopted affected the manner in which they were able to coordinate, control and monitor effective implementation. The ICO in IDS1 was able to carry this out effectively whereas the ICO in IDS2 could not.

In the IDS1, using the EPCM approach, the ICO engaged the subcontractors directly and was responsible for making payments for completed tasks. The approach also allowed them to recruit subcontractors from their supplier development network, thus ensuring the extension of patronage to the local suppliers. On the other hand, despite the position of NigCorp - an indigenously owned entity - as a champion of local content development, the adoption of the EPC contract strategy within IDS2 led to the absence of an interface between NigCorp and its subcontractors, as the main contractor assumed responsibility for such interactions. It was observed that any form of correspondence between the subcontractors and the ICO had to pass through the main contractor, thus making it difficult for the ICO to monitor effectively the progress made by the main contractor in adhering to the tenets of the NOGICD Act as dictated during project definition and procurement stages at the project delivery level. Considering the enormous powers wielded by the main contractor in IDS2 and the willingness of the ICO to implement SV effectively during the PP project, perhaps an EPCM contract would have been more advantageous to NigCorp.

For IDS3, a DCM contract was adopted. According to the project manager, the kind of contract strategy adopted made it imperative for city rail service (CRS) - the special-purpose vehicle - to engage local subcontractors when deemed economically feasible. He maintained that due to the long-term nature of the contract, the development of local subcontractors during the delivery stage became more of a business initiative, as such an initiative would lead to a reduction in maintenance costs. It is doubtful if CRS would have sought to uphold this business initiative if they had a different contracting strategy which did not bind them to long-term maintenance of the LR. Such considerations were not adhered to in IDS1 and IDS2 which were one-off projects. Although NigCorp has proposed to engage the EPM contractor over the long term, findings from the interviews indicate that the EPM contractor did not extend this feature to the suppliers.

Evidence of a direct relationship between the type of contracting strategy adopted in the procurement and delivery of infrastructure and the viability of the IDS is in conformity with the views held by Esteves et al. (2009), Schramm et al. (2010), and Tawiah and Russell (2005). In their contribution, Schramm et al. (2010) 


\section{Offprint provided courtesy of www.icevirtuallibrary.com Author copy for personal use, not for distribution}

maintain that clients should be careful in adopting a particular contracting strategy, insisting that clients should be sure of what they want to achieve and which contracting strategy would support them to achieve such objectives before selection. Esteves et al. (2009) admit that in most cases, the contract strategies adopted by mining and extractive companies in Australia debar local SMEs from participating in the delivery of major projects. Following from the accruing evidence from the cross-case analysis and the literature, it will appear that the kind of contracting strategy adopted by an ICO affects its ability to successfully drive SV implementation performance within its projects, its desire to do so notwithstanding.

\section{Conclusion}

This study forms an integral part of a doctoral study conducted into the development of a viable means of implementing SV through the procurement and delivery of infrastructure in Nigeria and the UK. It reports the findings from an investigation into the capability of a contracting strategy to influence the ICO's ability to drive successful SV implementation performance through the IDS. This study was premised on the views espoused by several scholars on the influence of contracting strategies on the attainment of SV implementation performance. However, a paucity of empirical studies investigating the influence of such strategies on an ICO's ability to drive successful implementation performance in accordance to the revered roles of client organisations (Boyd and Chinyio, 2006; Cherns and Bryant, 1984) was observed. This study set out to fill this void. Three distinct IDS case studies were selected in such a manner as to achieve both theoretical and literal replication. Subsequently, representatives of stakeholder groups were interviewed and project/policy documents reviewed. Findings from the three IDSs further confirmed that the contracting strategy adopted had a significant impact on the ICO's ability to drive through successful SV implementation performance across its delivery system (IDS). It was observed that contracting strategies involve the allocation of risks, delegation of responsibilities and governance of inter-organisational relationships among other facets between the ICO and its delivery system partners. Considering that inappropriate allocation of risks and/or delegation of responsibilities by the ICO as a result of the adopted contracting strategy could be detrimental to critical success factors for successful implementation - namely, support from top management, sufficient resource allocation, effective communication channels and presence of proper control and feedback mechanisms (Pinto and Slevin, 1987) - and thus negate the drive for successful SV implementation performance at project level by the ICO. The contracting strategy adopted also limits the ICO's ability to incentivise or penalise suppliers effectively. An unsuitable contracting strategy also affects the flow of information and knowledge between the ICO and the IDS. It is expected that ICOs desirous of successful SV implementation performance will ensure that the contracting strategy adopted is fit for purpose.

It is the intention of this article to contribute to the agitation for successful SV implementation performance in infrastructure delivery.
As such, while it does not lay claim to statistical generalisation, it makes an attempt at achieving analytic generalisation from a theoretical and literal replication perspective (Yin, 2009).

\section{REFERENCES}

Awuzie BO (2014) A Viable Infrastructure Delivery Systems Model for Achieving Socio-Economic Benefits in the Nigerian Oil and Gas Industry. PhD thesis, University of Salford, Salford, UK.

Awuzie BO and McDermott P (2014) A systems approach to assessing organisational viability - the case of an oil and gas infrastructure delivery project based organisation. International Conference on Construction in a Changing World (Amaratunga D, Haigh R, Ruddock L et al. (eds)). CIB, Heritance Kandalama, Sri Lanka.

Awuzie BO and McDermott P (2015) A conceptual model for evaluating infrastructure-based temporary multi-organisations. Built Environment Project and Asset Management 5(1): 103-120.

Balouga J (2012) Nigerian local content: challenges and prospects. IAEE Energy Forum 2012(3): 23-26.

Beer S (1984) The viable system model: its provenance, development, methodology and pathology. Journal of the Operational Research Society 35(1): 7-25.

Boyd D and Chinyio E (2006) Understanding the Construction Client. John Wiley \& Sons, London, UK.

Calderon C and Serven L (2008) Infrastructure and Economic Development in Sub-Saharan Africa. World Bank, Washington, DC, USA, policy research working paper. Carmichael DG (2000) Contracts and International Project Management. CRC Press, Boca Raton, FL, USA.

Carroll TN and Burton RM (2012) A contingency approach to designing project organizations: theory and tools. Engineering Project Organizaztion Journal 2(1-2): 5-14.

Cherns AB and Bryant DT (1984) Studying the client's role in construction management. Construction Management and Economics 2(2): 177-184.

De Blois M, Herazo-Cueto B, Latunova I and Lizarralde G (2011) Relationships between construction clients and participants of the building industry: structures and mechanisms of coordination and communication. Architectural Engineering and Design Management 7(1): 3-22.

Denscombe M (2007) The Good Research Guide for Small-Scale Research Projects. McGraw-Hill Education, Maidenhead, UK.

Dickinson M, Mcdermott P and Platten A (2007) Implementing policy through procurement: a longitudinal case study investigation. Journal of Construction Procurement 13(1): 4-13.

Dorée A, Van Der Wal G and Boes H (2011) Client leadership in sustainability: how the Dutch railway agency created $\mathrm{CO}_{2}$ awareness in the industry. In Proceedings of the 27th Annual Association of Researchers in Construction Management 
Conference, 5-7 September 2011, Bristol, UK (Egbu C and Lou ECW (eds)). Association of Researchers in Construction Management, Reading, UK, pp. 685-694.

DPER (Department of Public Expenditure and Reform) (2012) Procurement and Contract Strategy for Public Works Contracts. DPER, Dublin, Ireland.

Dubois A and Gadde LE (2002) Systematic combining: an abductive approach to case research. Journal of Business Research 55(7): 553-560.

Dubois A and Gadde LE (2014) "Systematic combining" a decade later. Journal of Business Research 67(6): 1277-1284.

Eisenhardt KM (1989) Building theories from case-study research. Academic Management Review 14(4): 532-550.

Eisenhardt KM and Graebner ME (2007) Theory building from cases: opportunities and challenges. Academy of Management Journal 50(1): 25-32.

Emmitt S and Gorse C (2006) Communication in Construction Teams. Routledge, London, UK.

Erridge A (2007) Public procurement, public value and the Northern Ireland unemployment pilot project. Public Administration 85(4): 1023-1043.

Esteves AM, Barclay MA and Brereton D (2011) Integrating social and economic impact assessment into local procurement strategy. Proceedings of the 1st Seminar on Social Responsibility in Mining (Brereton D, Pesce D and Abogabir X (eds)). Gecamin, Santiago, Chile (CD-ROM).

Esteves AM, Barclay MA, Samson D and Brereton D (2009) Local SME Participation in the Supply Chains of Australian Mining, Oil and Gas Companies. Centre for Social Responsibility in Mining, University of Queensland, Brisbane, Australia.

Hartley J (1994) Case studies in organisational research. In Qualitative Methods in Organisational Research (Cassell C and Symon G (eds)). Sage, London, UK, pp. 208-237.

Hill M and Hupe P (2009) Implementing Public Policy. An Introduction to the Study of Operation Governance. Sage, London, UK.

IUK (Infrastructure UK) (2013) Infrastructure Procurement Routemap: A Guide to Improving Delivery Capability. H.M Treasury, London, UK.

Kumaraswamy MM and Dissanayaka SM (1998) Linking procurement systems to project priorities. Building Research \& Information 26(4): 223-238.

Kvale S (2006) Dominance through interviews and dialogues. Qualitative Inquiry 12(3): 480-500.

Leiringer R, Green SD and Raja JZ (2009) Living up to the value agenda: the empirical realities of through-life value creation in construction. Construction Management and Economics 27(3): 271-285.

McDermott P (1999) Strategic and emergent issues in construction procurement. In Procurement Systems: A Guide to Best Practice in Construction (Rowlinson S and McDermott P (eds)). E \& FN Spon, London, UK, pp. 3-22.
Miles MB and Huberman AM (1994) Qualitative Data Analysis. Sage, Thousand Oaks, CA, USA.

MPR (Ministry of Petroleum Resources) (2010) Nigerian Oil and Gas Industry Content Development Act. Nigerian Security Printing \& Minting Company, Abuja, Nigeria.

Mulgan G (2010) Measuring social value. Stanford Social Innovation Review 8(3): 38-43.

Olsen BE, Haugland SA, Karlsen E and Johan HG (2005) Governance of complex procurements in the oil and gas industry. Journal of Purchasing and Supply Management 11(1): $1-13$.

Ottosson H (2012) Practical Project Management for Building and Construction. CRC Press, Boca Raton, FL, USA.

Pinto JK and Slevin DP (1987) Critical factors in successful project implementation. IEEE Transactions on Engineering Management 34(1): 22-27.

Public Services (Social Value) Act 2012 (2012) Elizabeth II. Chapter 3. Her Majesty's Stationery Office, London, UK.

Rowlinson S (1999) A definition of procurement systems. In Procurement Systems: A Guide to Best Practice in Construction (Rowlinson S and Mcdermott P (eds)). E \& FN Spon, London, UK, pp. 23-48.

Russell S (2013) Journey to Impact: A Practitioner Perspective on Measuring Social Impact. Birmingham Midland Heart/ HouseMark, Birmingham, UK.

Rwelamila P, Talukhaba A and Ngowi A (2000) Project procurement systems in the attainment of sustainable construction. Sustainable Development 8(1): 39-50.

Schramm C, Meißner A and Weidinger G (2010) Contracting strategies in the oil and gas industry. Pipeline Technology 2010(Special Edition): 33-36.

Snieska V and Simkunaite I (2009) Socio-economic impact of infrastructure investments. Inzinerine Ekonomika Engineering Economics 3(1): 16-25.

Stoker G (1998) Governance as theory: five propositions. International Social Science Journal 50(1): 17-28.

Tawiah PA and Russell AD (2005) Influence of procurement mode on innovation potential in infrastructure project delivery. Proceedings of the 33rd CSCE Annual Conference, Construction Specialty Conference, Toronto, Ontario, Canada, 2-4 June.

Taylor-Powell E and Renner M (2003) Analyzing Qualitative Data. University of Wisconsin, Madison, WI, USA.

Walker D and Rowlinson S (2007) Procurement Systems: A Cross-Industry Project Management Perspective. Routledge, London, UK.

Warner M (2011) Local Content Solutions: Participation of Domestic Industry in Procurement for Oil, Gas and Mining Projects. Greenleaf Publishing, Sheffield, UK.

Watermeyer RB (2000) The use of targeted procurement as an instrument of poverty alleviation and job creation in infrastructure projects. Public Procurement Law Review 9(5): 226-250. 
Watermeyer RB (2003) Implementing preferential procurement policies in the public sector in South Africa. Journal of South African Institution of Civil Engineering 45(3): $11-22$.

Wells J and Hawkins J (2008) Increasing Local Content in the Procurement of Infrastructure Projects in Low Income
Countries. Engineers Against Poverty and Institution of Civil Engineers, London, UK, pp. 6-7.

Wood C and Leighton D (2010) Measuring social value: the gap between policy and practice. Undercurrent 2010(2): 7-9.

Yin RK (2009) Case Study Research Design and Methods. Sage, Thousand Oaks, CA, USA.

\section{WHAT DO YOU THINK?}

To discuss this paper, please submit up to 500 words to the editor at journals@ice.org.uk. Your contribution will be forwarded to the author(s) for a reply and, if considered appropriate by the editorial panel, will be published as a discussion in a future issue of the journal.

Proceedings journals rely entirely on contributions sent in by civil engineering professionals, academics and students. Papers should be 2000-5000 words long (briefing papers should be 1000-2000 words long), with adequate illustrations and references. You can submit your paper online via www.icevirtuallibrary.com/content/journals, where you will also find detailed author guidelines. 